\title{
School Adjustment: A Case of an Adolescent Diagnosed with Specific Learning Disabilities
}

\author{
Garyfalia Charitaki, Yiolanda Marasidi, Spyridon-Georgios Soulis \\ Faculty of Primary Education, University of Athens, Athens, Greece \\ Email:lcharitaki@hotmail.com
}

How to cite this paper: Charitaki, G., Marasidi, Y. and Soulis, S.-G. (2018) School Adjustment: A Case of an Adolescent Diagnosed with Specific Learning Disabilities. Open Journal of Social Sciences, 6, 15-26. https://doi.org/10.4236/jss.2018.64002

Received: February 27, 2018

Accepted: April 15, 2018

Published: April 18, 2018

Copyright $\odot 2018$ by authors and Scientific Research Publishing Inc. This work is licensed under the Creative Commons Attribution International License (CC BY 4.0).

http://creativecommons.org/licenses/by/4.0/

\section{(c) (i) Open Access}

\begin{abstract}
This research basically aims to investigate the School Adjustment of an adolescent diagnosed with Special Learning Disabilities. More specifically, the adolescent's Social Traits, Motives, and Personal Adjustment are being studied. For the purposes of the research, the qualitative methodological approach was chosen. Also, semi-structured interviews were conducted, based on the School Adjustment Scale (Power \& Cotterell, 1979) [1]. Results showed that the adolescent with Special Learning Disabilities faces adjustment problems regarding general satisfaction from school and self-confidence for school performance. Anxiety, lack of self-confidence and reduced social skills are the main obstacles for School Adjustment. Results are discussed concerning the development of social, communicational and general attainments in adolescents with Specific Learning Disabilities.
\end{abstract}

\section{Keywords}

Specific Learning Disabilities, Adolescent, School Adjustment

\section{Introduction}

Today's educational reality is characterized by an increasing differentiation of the student population in terms of cognitive, emotional and social development. Undoubtedly, the effective use of written speech determines the pupil's integration and success in social and professional reality (Porpodas, 2002) [2]. Recently, significant efforts have been made to change the education system in order to achieve for children with Specific Learning Disabilities a smooth transition from nursery to primary school. At the same time, there is a focus on children's participation in classroom activities (Sebba, 2011) [3].

Specific Learning Disabilities (SLD) is a term that refers to a large group of disorders with an impact on spoken and written speech, mathematics and more 
generally on the development and use of a child's learning strategies (Porpodas, 2002) [2].

The incidence of Special Learning Disabilities varies from country to country because their diagnosis is influenced by both linguistic elements and diagnostic tools. The frequency of the student population varies from $3 \%-15 \%$, while higher rates are observed in deprived groups and in western societies (Maridaki-Kassotakis, 2005) [4]. More generally, about $15 \%-20 \%$ of the student population has to deal with a variety of problems or difficulties in a learning area. In relation to gender, girls have a lower percentage of serious difficulties as opposed to boys (Maridaki-Kassotakis, 2005) [4].

Recently, many researchers are interested in social and emotional development not only in children with Autism Spectrum Disorder, but also in those diagnosed with Specific Learning Disabilities. School (Charitaki, 2015) [5], and in particular the classroom, is one of the most important parameters of socialization, since it is related to the adjustment of each child to the social environment (Legaki, 2007) [6]. The purpose of this research is to study the school adjustment in children diagnosed with Specific Learning Disabilities, in relation to Social Traits, Motives, and Personal Adjustment.

Despite the increasing interest in students' school adjustment, much of the research has focused only on typically developing children. Consequently, through this research an attempt is being made to bridge the lack of knowledge in this field. More specifically, the general satisfaction, the social satisfaction in correlation to school community and the self-confidence for academic achievements in children diagnosed with SLD are examined.

\section{Theoretical Background}

Neuropsychology, Computer Science and Applied Behavior Analysis are different scientific areas which contributed to the development of different approaches to Specific Learning Disabilities. Neuropsychological knowledge has greatly helped to study SLD, though the Brain Structure \& Function in those children (Sebba, 2011) [3]. Indicatively, the hemispheres, the speech centers, the orientation, the cerebral dysfunction, which are manifested in the electroencephalogram and helped to understand the learning difficulties, are examined for those purposes (Sebba, 2011) [3]. The second sector, ICT, adopts models related to the recruitment, processing and expression of information. In addition, it focuses on the manipulation of information from the Central Nervous System (Legaki, 2007) [6]. The third approach relates to behavior, determined through observation and explainedby the determination of the relation between a stimulus and the specific reaction in relation to it. (Micheliannis \& Tzenaki, 2000. Nicholas, 2007) [7] [8]. In conclusion, all of these theories have contributed and continue to contribute to a fuller understanding of SLD.

The term "Adjustment" is defined as the result of a dynamic and continuous process of people in order to achieve effective functioning in daily activities (Zafiriadis, 2002) [9]. A basic prerequisite for smooth adjustment is the existence of 
incentives. In general, adjustment is the smooth and creative integration of the individual into social life (Zafiriadis, 2002) [9]. The term "adjustment" has its roots in psychology and pedagogical science, referring to the psychological adaptability of the individual as a universal human phenomenon. In a nutshell, it is the ability of a person to dynamically adapt to the changes that occur in the environment (Dockett \& Perry, 2001) [10]. Therefore, with the term "school adjustment" we refer to the pupil's ability to adapt to the changes and conditions of the school. The students' adjustment is directly related to their self-image, as well as to their interaction with their classmates and educators (Dockett \& Perry, 2001) [10].

Systematic studies have shown that SLD constitutes a complex problem and, in addition to their impact on the cognitive-learning domain, can adversely affect the emotional and social development of children (Floratou, 2002) [11]. Children with SLD tend to experience frustration more frequently than their peers (Carpathian, 1994) [12]. The basic reason for this phenomenon seems to be related to their low school performance.

More generally, negative emotions and consequently behavioral problems arise not only from oneself, but also from interpersonal self-regulation (Kandarakis, 2004) [13]. In addition, they tend to have more emotional problems, such as low self-esteem, depressive symptoms, loneliness, anxiety and aggression (Kandarakis, 2004) [13]. Such problems can be grouped into three groups: a) emotional disorders such as fear, cowardice, anxiety, b) cognitive disorders such as nail biting, anorexia, insomnia, and c) behavioral disorders such as anger and aggression. Finally, it should be mentioned that because of their poor school performance, these children may experience rejection at school by peers and teachers, but also by their parents, and as a result their problematic behavior occurs at school, home and other places (Bender, 2004) [14].

Students with SLD generally experience higher levels of stress than their peers. High stress is usually associated with deficits in cognitive processing (Bender, 2004) [14]. Also, anxiety level is increasing in specific periods, such as exams (Pandeliadou, Patsidimou \& Botsas, 2004) [15]. We conclude that their low performance is often related to the increase of the level of anxiety (Pandeliadou, Patsidimou \& Botsas, 2004) [15]. On the other hand, adolescents with SLD do not have strong motivations and they tend to adopt more passive learning styles. Reduced motivations adversely affect the adolescent's cognitive development and this results in difficulties in achieving high level of attainments (Pandeliadou, Patsidimou \& Botsas, 2004) [15]. More specifically, when there is a systematic failure, pessimistic views for their intellectual abilities are held which in turn result in reduced motives about learning. They usually develop dependence on others and seek social support (Panteliadou, Patsidimou \& Botsas, 2004) [15].

The importance of problems related to social development in children with SLD is highly correlated to their social skills, school failure and school adjustment. The phenomenon of adolescents being treated with hostility, being subjected to strong criticism and possibly being punished for no real reason may 
result in the development of various neurotic mechanisms and antisocial behavior (Zakopoulou, 2002) [16]. Adolescents with SLD are often faced with difficulties due to their low self-confidence and popularity (Smith, 2004) [17]. Social relations in adolescents with SLD derive from the development of self-regulation skills (Wong, 1996) [18]. On the contrary, their inappropriate behavior seems to be related to misinterpretation of messages, difficulty in oral speech and adjustment (Kavale \& Forness, 1996) [19]. Still, in difficult situations they do not respond appropriately and cannot defend themselves (Kavale \& Forness, 1996) [19].

In addition, adolescents with SLD often have no friends (especially towards the end of the school year) because they cannot correctly interpret various social behaviors. Finally, research has shown that the social acceptance of adolescents with SLD depends on the teaching environment and their integration into it (Polichroni, 2006) [20]. According to Polichroni (2006) [20], adolescents with difficulties in reading seem to have more negative self-perception, in relation to their psychosocial adjustment, than their peers. Furthermore, the rejection that they experience has a major impact on their school adjustment as they have to make a great effort to be accepted in the school community. Finally, it is mentioned that a holistic approach which includes psychosocial support and school intervention is needed as well (Polichroni, 2006) [20]. Another research, by Martimanianakis (2015) [21], on the psychosocial adjustment of adolescents with and without SLD has brought to light important findings. The results showed lower psychosocial adjustment and self-esteem for students with SLD, as well as lower percentage of social competence and higher level of behavioral problems. However, there were no differences between the two groups of participants in school and emotional adequacy (Martimanianakis, 2015) [21].

\section{Method}

\subsection{Research Design}

This research basically aims to investigate the School Adjustment of a case of an Adolescent diagnosed with Specific Learning Disabilities. For the aforementioned purpose, a qualitative approach was chosen.

\subsection{Sample-Participants}

Purposeful Sampling was chosen in order to include cases of participants on preconceived criteria in this research. The sample consisted of an adolescent diagnosed with SLD, aged 15 years old, one of the parents of the child and the educators who taught mathematics and Greek courses both in typical and resources classrooms. Also, the educator who taught English language in the typical classroom participated in the research.

\subsection{Research Tools}

For the purposes of data collection, the methodological technique of semi- 
structured interview was selected. The list of interview questions was based on the School Adjustment Scale. Additionally, the entire School Adjustment Scale was administered to the adolescent diagnosed with SLD in order to collect data for the self-perceived school adjustment.

\section{Results}

The first research question raised concerns over the level of general satisfaction of the child with special learning difficulties with the school. According to her answers to the School Adaptation Scope's questions regarding her satisfaction with the school, she gave the answer "ALWAYS", at $8.3 \%$ (for the answers to the questions in the question), that she would be pleased at school, if she did not have so much homework.

Still, she responded $33.3 \%$ to the "SOMETIMES" response to the level of interest that she has for school, how happy she is from school, about the fatigue she feels from school and how much interest most students show for what is happening in the school environment. She also gave the answer "OFTEN", $33.3 \%$, concerning how much she longs to come to school, how easily she can sit with the pupil she wants, how much she loves school in relation to other children, and how most of the schoolwork is useless. In addition, she gave the $25 \%$ answer "NEVER," about how messy the school framework is and how nobody cares about what is happening to her. It is noted that in the majority of the questions posed to the student the evaluation resulting from her words is low with 91.7\% being from "SOMETIMES" and below with $58.4 \%$ being either "NEVER" or "OFTEN".

The second research question concerns the social satisfaction of the child with special learning difficulties with her relations with the faculty of the school community, with her classmates and professors. According to the answers she gave to the School Adaptation Scope she gave the answer "ALWAYS" at 7.6\%, about how nervous she is when her teachers do not help her when she needs them. She then responded 53.8\% to "SOMETIMES" about how she loved her teachers, how much her classmates were asking for her company, how her teachers helped her learn the lessons, how much they loved her classmates and how friendly and interesting the professors are. The "OFTEN" response, at a rate of $15.3 \%$, was given about how much she was afraid to ask her professors for clarification when she did not understand something, and whether she believed her teachers did not like her, while the answer "NEVER" 23\% was given in terms of no one paying her attention to the school environment and not having as many friends as she wanted. It is noted that in the majority of the questions posed to the student the evaluation resulting from her words is low with $92.1 \%$ being from "“"Average" and below and with 38.3\% being either "Never", or "Often".

The third research question raised is related to the level of self-confidence of the child with special learning difficulties for her success in the school context. Regarding the answers she gave to the School Adaptation Scope questions about her satisfaction with the school, she gave the answer "ALWAYS", at $18.2 \%$, 
about the concern that she did not write well during competitions and how much anxiety she had during the contest. In addition, she gave the answer "SOMETIMES", at a rate of 45\%, that she did not do well at school lessons, that she was hardly getting into her class, that she was disturbed every time her professor asked various questions, that school children with learning difficulties are not doing well, that children with learning difficulties, if they try, will not become good students and how delighted they are with the progress they have in the lessons. In addition, she gave the answer "OFTEN", 27\%, about how well she goes to the lessons and about how afraid she is of saying something silly during the lesson. Finally, she gave the answer "Never", at a rate of $9 \%$, as to how sure she is to write well every time they have a test. It is noted that in the majority of the questions posed to the student the evaluation resulting from her words is low with $81 \%$ being from "Average" and below and with $36 \%$ of them being either "Never" or "Often ".

The fourth research question raised concerns over how teachers and the parent of a child with special learning difficulties perceive their general satisfaction with the school. The answer was given through the co-conventions made with teachers and parents. In particular, for the first question, "Is there a disruption to the class which results in loss of concentration? Can you give an example?" The majority of the teachers answered that usually there is no fuss during their lessons and that there is not much discomfort allowing, thus, them to remain concentrated. A characteristic excerpt of the philologist's answer is the following: "This particular issue is quite difficult, as there are many children who make a fuss. Also, the English teacher said: "there is no particular disruption during the course but if some turmoil is caused it is due to the difficulty of understanding the exercises and the lack of interest in learning English." In addition, the special educator of the integration section considers that there is an inconvenience only when the lesson takes place in the last school periods and the child is "tired".

Then, with regard to the general satisfaction of the school of the child with learning difficulties by teachers, the question "Is there anxiety while writing a test?", the majority responded how he noticed her to be quite anxious. On the other hand, the parent when asked "Do you think your child is happy going to school?" he replied "she does not wake up easily for school, she does not want to go to school when she writes a test but is very eager to go and see her girlfriends. In fact, he added that many times she has pretended to be sick to avoid going to school. Regarding the anxiety she has during the contests, the parent commented "..despite the stress she has when she is studying she is doing great, but she does not sleep well in the evening before a test, especially on the exam."

Continuing, the fifth research question raised concerns over the teachers and the parent of the child with special learning difficulties and the child's relations with the faculty of the school community perceive. To the question "Is the child afraid to ask his questions?" The answer was unanimous and it was affirmative. The mathematician added, "She has several mathematical gaps and she is afraid 
to lift her hand." The philologist thinks that the child does not want to be exposed to her classmates. "That's why she sometimes has questions that she is ashamed to ask. On the other hand, the special educator agreed that the child was afraid to ask questions at the beginning of the year, but due to the fact that only two students attend the integration section this year, she gained courage during the year and asked questions without fear of being exposed. The parent answered this question: "At home, she has no fear of asking herself or her father for a question."

During the interview, teachers were asked about the student's socialization and specifically: "Are the other school children or classmates looking for her company?". In addition, in the same question, the parent responded that the child in the municipal "was very introverted and had only one girlfriend as she was ashamed because she thought she had something bad." However, over the years and with the help of her family and of her teachers, she has become more confident and has acquired more friends.

The sixth research question that was answered during the interview with the teachers and the parent concerns how they perceive the success of a child with special learning difficulties at school. To the question "Can children with learning disabilities be good students if they try?" all teachers responded positively, including the parent, provided they had the necessary help from a specialist educator. A characteristic excerpt of the answer of the special educator of the integration section was "..children with special learning difficulties can become very good students and become brilliant scientists or follow a very good career if they live in a supportive environment characterized by understanding, patience and are given the necessary confidence to move forward."

In addition, to the question "Are you happy with the child's progress in the lessons?", the English teacher replied that she is happy because "through their collaboration, the student evolves, progresses and matures as a teenager." The mathematician replied, "It could be even better and the part of integration into its progression is helping it significantly". Finally, the parent is also pleased, as she said that through her whole course of study the progress she has made is great and she says "...I will always be beside her to help her in everything because I love her very much!"

\section{Discussion}

Qualitative analysis showed feelings of dissatisfaction of the adolescent with SLD with school due to their continuous effort to respond to typical academic attainments (Libaniou, 2004) [22]. Also, several adolescents with SLD find themselves inadequate in recognition and satisfactory response to environmental or group communication (Kandarakis, 2004) [13]. Deficiencies in social skills, often, are expressed through loneliness and lead educators or parents to have pessimistic perceptions about adolescents' integration to school. This results in problems greater than those of academic content that can be addressed drasti- 
cally with diversified teaching methods and technical means (Kandarakis, 2004) [13].

Children with learning disabilities face interpersonal problems, such as creating and maintaining friendly relationships with others, as opposed to children who do not have a learning disability. Often, children with learning disabilities are recognized as less acceptable than their classmates, with the risk of being isolated by teachers and classmates. Furthermore, they are chosen less often to play because they have lower social standing than their other classmates] Bimbu, Polychroni \& Hatzichristou, (2010) [23]. It is equally important that children with learning disabilities are more willing to participate in antisocial activities and are less willing to interact with educators and classmates. (Kandarakis, 2004) [13]. It is obvious, therefore, that the level of social satisfaction of the child is not sufficient for the reasons mentioned above.

As a result, the level of self-confidence of a child with learning disabilities is low, as confirmed in the theoretical part, these children face a lot of stress and difficulty during the lessons which is a blow to their self-confidence. In particular, a lack of self-confidence creates a chain of psychological problems that gradually erode and sometimes destroy their self-esteem (Kandarakis, 2004) [13]. Consequently, students with learning disabilities are often stigmatized by their classmates and by the teachers and are considered to be odorous, resulting in few or no friends or joining antisocial groups (Kandarakis, 2004) [13]. Lack of self-confidence is closely linked to behavioral problems, so repeated failures in relationship with peers and school requirements lead to emotional problems that are often expressed with negative and unacceptable behaviors. The lack of social skills and thus self-confidence leads to the increasing probability of problems of intra-person or interpersonal adaptation. (Bimbu, Polychroni, \& Hatzichristou, 2010) [23]. It is a fact that failure at school causes intense mental pain and children feel that they are marginalized and treated by their peers with anger. The dangerous point in this is in the feelings of inadequacy and inferiority at the personal and social level that the child feels. Thus, the child shapes his or her personality with feelings of weakness, inadequacy and disability, resulting in a negative image of himself or herself (Anagnostopoulos \& Sini, 2005) [24].

Consequently, it was observed how teachers perceive that the child has difficulty coping with his anxiety, which stems from his reduced self-confidence due to specific learning difficulties. On the other hand, the parent understands the child's low satisfaction from school as he observes the reduced interest and the great anxiety. It is a fact that teenagers with learning difficulties cannot easily cope with stressful situations such as tests. Although research has not shown that these students face higher levels of anxiety by circumstance than their typical peers, they are experiencing higher general anxiety as a characteristic of their personality (Bender, 2004) [14]. The high anxiety of adolescents with learning difficulties that is considered to be characteristic of them could be attributed to problems of cognitive deficits that lead to difficulties in recognizing situations and considering that they are experiencing a real problem (Margalit \& Shulman, 
1986) [25]. Teenagers with learning difficulties experiencing anxiety, either do not talk to anyone, or deny the existence of the problem they face. This denial is accompanied by even higher anxiety or other emotional problems and often by physical reactions (Geisthardt \& Munsch, 1996) [26]. The particular case, where anxiety levels in a particular situation are significantly higher than those of their typical classmates, is the time when the stressful period of the examinations begins (Anagnostopoulos \& Sini, 2005) [24]. Their level of anxiety is skyrocketed, due to their low academic skills, their focus on avoiding low performance coupled with their inability to get away from it all (Huntingston \& Bender, 1993) [27].

Consequently, children with special learning difficulties face difficulties in their relationship with the faculty of the school community, whether they are their teachers or their classmates. More specifically, these difficulties are limited to anxiety and do not expose them to any question (Livaniou, 2004) [22]. In general, children with special learning difficulties are introverted and locked in themselves and need help from teachers and parents to overcome those problems. More specifically, the factors that are considered in relation to the social development of learning difficulties are their social behavior and social skills in relation to the persons they are cohabiting, the ability to recruit and interpret social stimuli from others, and social acceptance by their peers (Little, 1993) [28]. The existence of social skills is a prerequisite for creating social relations and friendships between individuals (Wong, 1996) [18]. Children with learning disabilities are less polite and cooperative with people who are socializing and rarely start a social interaction with them (Milne \& Schmidt, 1996) [29]. This is because they have a poor ability to interpret rightly and properly the stimuli that occur in every social circumstance (Kavale \& Forness, 1996) [19]. Thus, mistakes are often made in the interpretation of linguistic data and are also unable to adopt appropriate social behaviors that will lead them to avoid unpleasant situations (Sisterhen \& Gerber, 1989) [30].

On the other hand, relations between teachers and students are created and developed within the classroom and vary according to the atmosphere and climate prevailing in the particular school, the methods and techniques the teacher uses to encourage these relationships, and even the characteristics of his personality and his counseling skills (Livaniou, 2004) [22]. Sometimes we observe that the teacher's attitude toward the student is totally opposed to what he or she ought to be. Thus, the teacher can be very demanding and not provide the necessary encouragement which results in children losing their interest to learn. Unfortunately, many teachers are still unable to understand the relationship between the child's difficulty in learning how to read and the psychological development that affects him or her (Nicholas, 2007) [8]. Lack of understanding by the teacher and parents prompts them to insist more, to exert pressure on the child to read and often to punish the child for lack of progress (Kandarakis, 2004) [13]. Consequently, creating a positive or negative atmosphere within the classroom is largely the sole responsibility of the teacher. The teacher has to cul- 
tivate a healing relationship with his students based on principles such as authenticity in communication, acceptance, trust and understanding. Only then will the students want to take initiatives, get less stressed and perform better (Kandarakis, 2004) [13].

It is therefore easy to see that the teachers and the parent of the child with special learning difficulties are satisfied with the course because with the appropriate help they are receiving. The parents' role in the success of this school effort is very important because they have many opportunities to positively influence their children and motivate them (Polichroni, 2006) [20]. The difficulties of the child at school are best addressed when, alongside learning rehabilitation, efforts are made to smooth out the emotional difficulties that the child and the parents themselves are having. The parents should feel helpful and confident in their ability to be supportive of the child. So, they can help their children to cope with any difficulties they might encounter and to obtain a healthy identity (Livaniou, 2004) [22]. At this point, it should be noted that the role of the teacher is also extremely important. Providing objective information on student status and stable support can make it easier for parents to make appropriate educational decisions (Zakopoulou, 2002) [16].

\section{Conclusions}

Adolescents' schooling is directly related to their self-image, as well as to their interaction with their classmates and educators (Dockett \& Perry, 2001) [10]. It is therefore clear that they are experiencing difficulties in their School Adjustment (Zafiriadis, 2002) [9]. This was also apparent from the findings of this study, from which we conclude adolescents with SLD have difficulties in School Adjustment. The School Adjustment of the adolescent with SLD must be designed and implemented by parents, special educators and psychologists. Counseling seems to be important in order to support parents to cope with behavior problems. It is also important for parents to be informed about the problems of the adolescent in School Adjustment and to set realistic goals for the adolescent's academic attainments.

Teachers tend to overlook the importance of emotions in developing academic attainments. Teachers can help students with SLD to develop strategies in order to deal with their anxiety (Nabuzoka, 2000) [31]. Setting clear and sensible goals is of major importance since they can promote adolescent's smooth adaptation and have long-term, positive results (Livaniou, 2004) [22]. In addition, educators' positive attitudes towards adolescents with SLD, the prevalence of democracy in the school community, and the involvement of parents in the education can lead to an improvement in their self-esteem and hence the improvement of school adjustment (Nabuzoka, 2000) [31].

The socialization of adolescents with SLD does not fulfill their need for recognition and acceptance by other people. They experience negative feelings towards peers, parents and teachers and all this greatly affects their school adjustment and motivation (Zafiriadis, 2002) [9]. 


\section{References}

[1] Power, C. and Cotterell, L. (1979) Students in Transition. A. Longitudinal Study of Student Behavior and Development in Different Primary and Secondary School Environment. The Flinders University of South Australia School of Education.

[2] Porpodas, K. (2002) The Reading. Patra.

[3] Sebba, J. (2011) Personalisation and Special Educational Needs. Policy Paper 5, Sixth Series.

[4] Maridaki-Kassotaki, A. (2005) Learning Difficulties: Psycho-Pedagogical Approach. Ellinika Grammata, Athens.

[5] Charitaki, G. (2015) The Effect of ICT on Emotional Education and Development of Young Children with Autism Spectrum Disorder. Procedia Computer Science, 65, 285-293. https://doi.org/10.1016/j.procs.2015.09.081

[6] Legaki, L. (2007) A Dynamic Approach to Learning Disabilities. In: Vlassopoulou, M., Giannetopoyloy, A., Diamanti, M., Kirpotin, L., Levantis, E., Leytheri, E. and Sakellariou, G., Eds., Linguistic Difficulties and Written Speech in the Context of School Learning (Conference Proceedings), Grigoris, Athens.

[7] Mixelogianni, I. and Tzenaki, M. (2000) Learning Difficulties. 2nd Edition, Grigoris, Athens.

[8] Nikolaou, S.M. (2007) Management of School-Class Problems: Behavioral Problems. In: Makri-Botsari, E., Ed., Issues of Management of School-Class Problems, Pedagogical Institute, Athens.

[9] Zafeiriadis, K. (2002) Pupils from the Special Classes, Who Attend High School: Social and Psychological Characteristics, Motivation for Learning, School Performance and Adaptation. University of Aegean.

[10] Dockett, S. and Perry, B. (2001) Starting School: Effective Transitions Early Childhood Research and Practice.

[11] Floratou, M.M. (2002) Learning Disabilities and Not Laziness. Odysseus, Athens.

[12] Karpathiou, X. (1994) Dyslexia. Ellinika Grammata, Athens.

[13] Kandarakis, A.G. (2004) Learning Disabilities Coexist with Behavioral Problems. X.T. Savvalas.

[14] Bender, W.N. (2004) Learning Disabilities. Characteristics, Identification and Teaching Strategies. 5th Edition, Pearson Education Inc., Boston.

[15] Panteliadou, S., Patsiodimou, A. and Mpotsas, G. (2004) Learning Difficulties in Secondary Education. Publications Adaction S.A.

[16] Zakopoulou, B. (2002) Early Detection of Trends to Show Symptoms of Dyslexic Behavior during Preschool Age. Thesis, University of Ioannina, Ioannina.

[17] Smith, R. (2004) Learning Disabilities the Interaction of Students and Their Environments. Fifth Edition, Pearson Allyn \& Bacon, Boston.

[18] Wong, B. (1996) Metacognition and Learning Disabilities. In: Wong, B.Y.L., Ed., $A B C s$ of Learning Disabilities, Academic Press Inc., San Diego, 120-139.

[19] Forness, S.R., \& Kavale, K.A. (1991) Social Skills Deficits as Primary Learning Disabilities: A Note on Problems with the ICLD Diagnostic Criteria. Learning Disabilities Research \& Practice, 6, 44-49.

[20] Polychroni, F. (2006) The Psychosocial Characteristics of Pupils with Special Learning Difficulties. In: Papadatos, Ed., Issues of Learning Disabilities and Dyslexia, Center for the Study of Physiology and Education, University of Athens, Athens.

[21] Martimianaki, A. (2015) Psychosocial Adaptation and Self-Esteem of Pupils with 
and without Learning Difficulties. Department of Primary Education of the University of Patras, Patra.

[22] Livaniou, E. (2004) Learning Disabilities and Behavioral Problems in Normal School Class. Kedros, Athens.

[23] Bimbu, A., Polychroni, F. and Hatzichristou, Ch. (2010) Special Learning Difficulties, Dyslexia. Classification, Evaluation and Intervention. 5th Edition, EllinikaGrammata, Athens.

[24] Anagnostopoulos, D. and Sini, A. (2005) Disorders of School Learning and Psychopathology. BHTA Medical Arts, Athens.

[25] Margalit, M. and Shulman, S. (1986) Autonomy Perceptions and Anxiety Expressions of Learning Disabled Adolescents. Journal of Learning Disabilities, 19, 291-293. https://doi.org/10.1177/002221948601900508

[26] Geisthardt, C. and Munsch, J. (1996) Coping with School Stress. A Comparison of Adolescents with and without Learning Disabilities. Journal of Learning Disabilities, 29, 287-296. https://doi.org/10.1177/002221949602900307

[27] Huntington, D.D. and Berder, W.N. (1993) Adolescents with Learning Disabilities at Risk? Emotional Well-Being, Depression, Suicide. Journal of Learning Disabilities, 26, 159-166. https://doi.org/10.1177/002221949302600303

[28] Little, S.S. (1993) Nonverbal Learning Disabilities and Socioemotional Functioning: A Review of Recent Literature. Journal of Learning Disabilities, 26, 653-665. https://doi.org/10.1177/002221949302601003

[29] Milne, T.A. and Schimdt, F. (1996) Self-Esteem in Learning Disabled Children: The Role of Social Competence. Meeting of the 26th International Congress of Psychology, Montreal.

[30] Sisterhen, D.H. and Gerber, P.J. (1989) Auditory, Visual, and Multisensory Nonverbal Social Perception in Adolescents with and without Learning Disabilities. Journal of Learning Disabilities, 22, 245-249. https://doi.org/10.1177/002221948902200408

[31] Nabuzoka, D. (2000) Children with Learning Difficulties: Social Understanding and Adjustment. Blackwell, BPS Books, Cambridge. 